\title{
CORRECTION
}

\section{Correction to: Elaboration of bio-based building materials made from recycled olive core}

\section{Correction to: MRS Energy \& Sustainability https://doi.org/10.1557/s43581-021-00006-8}

This article was updated to correct the corresponding author as Mohamed Guendouz.
Djamila Boukhelkhal and Mohamed Guendouz (D), LME Laboratory, University of Medea, Medea, Algeria

Alexandra Bourdot, LMT - Laboratoire de Mécanique et Technologie, Université Paris-Saclay, ENS Paris-Saclay, CNRS, 91190 Gif sur Yvette, France

Hanane Cheriet and Kaouther Messaoudi, Civil Engineering Department, University of Medea, Medea, Algeria

Address all correspondence to Mohamed Guendouz at guendouz.mohamed@ univ-medea.dz

Published online: 17 August 2021 